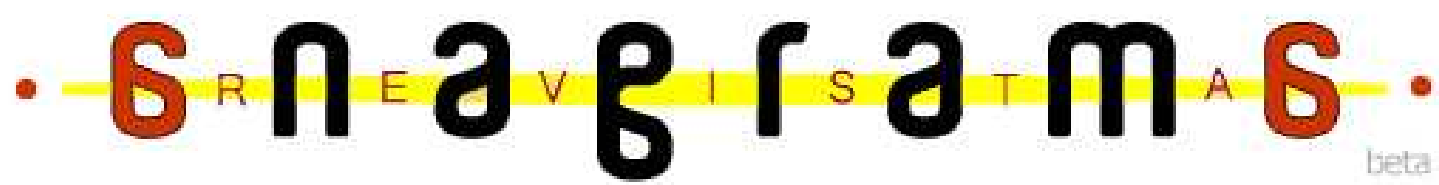

\section{Os Pais e a Classificação Indicatiua: uma relação fundamental ${ }^{1}$}

Brenda Lyra Guedes ${ }^{2}$

\section{Resumo}

Tendo em vista a presença marcante e atuante dos meios de comunicação para com o universo infanto-juvenil, registrou-se a necessidade do desenvolvimento de políticas públicas e outros tipos de iniciativas rumo a uma caminhada em prol da defesa e da promoção dos direitos de uma minoria específica, a saber, as crianças e os adolescentes brasileiros. Neste contexto, a Classificação Indicativa, respaldada pelo Ministério da Justiça, em parceria com organizações civis, foi identificada como tal e teve sua proposta discutida e debatida por pais, e/ou responsáveis, residentes na cidade de Fortaleza-CE (Brasil), numa coleta de informações sobre a adequação e a validação do instrumento; especificamente no que diz respeito às relações existentes entre a comunicação, a educação e a família. Além disso, foi posta à prova a hipótese de que a Classificação Indicativa existe para determinadas famílias e crianças, tendo esta sido confirmada através da realização de uma pesquisa de caráter qualitativo e quantitativo.

Palauras-chaue: Infância; Mídia; Educação; Classificação Indicativa

1. กoções Situacionais:

Já em vigor por, aproximadamente, 10 anos a proposição do pesquisador, norteamericano, Neil Postman (1999) sobre o desaparecimento da infância faz-se relevante numa discussão sobre a situação das crianças na contemporaneidade. Segundo o autor, a infância estaria desaparecendo à medida que ocorrem determinadas mudanças sociais (dentre elas cita-se o surgimento e o aprimoramento tecnológico dos meios de comunicação de massa) que caminham na contramão da possibilidade de controle sobre a informação e da necessidade de uma aprendizagem gradativa.

\footnotetext{
${ }^{1}$ Artigo baseado e reorganizado a partir do Trabalho de Conclusão de Curso de Brenda Guedes, orientado por Alessandra Alcântara.

${ }_{2}^{2}$ Estudante da graduação no curso de Comunicação Social - Publicidade e Propaganda da Universidade de Fortaleza; Pesquisadora Voluntária do Grupo de Pesquisa da Relação Infância e Mídia (GRIM); Assistente de Comunicação da Associação dos Docentes da UNIFOR.
} 
O novo ambiente midiático que está surgindo fornece a todos, simultaneamente, a mesma informação. A mídia eletrônica acha impossível reter quaisquer segredos. Sem segredos, evidentemente, não pode haver algo como a infância. (POSTMAN, 1999, p. 94)

Ou seja, conforme vão se esvaindo as zonas de segredos pertencentes apenas ao mundo adulto, e novas pontes - que anulam o abismo entre as informações reservadas para os mais velhos e os conteúdos exclusivos para os mais novos - vão se erguendo; iria desaparecendo a infância.

Sem dúvida, o aprimoramento tecnológico e o desenvolvimento e a multiplicação dos meios de comunicação proporcionaram uma nova atmosfera à realidade dos meninos e meninas da contemporaneidade. Vivemos em uma sociedade onde a informação tem contribuição crucial na definição dos campos de atuação e da voz à qual têm direito os seus sujeitos. O conteúdo daquilo que vamos encontrar ao colocarmos os pés fora de casa, ou mesmo ao acionarmos um dos botões da "caixa preta" que ocupa espaço central na disposição de nossa sala de estar residencial, é pouco previsível. E todos estes elementos, definitivamente, contribuem para que aspectos, anteriormente, reservados para serem destinados a adultos cheguem aos pequeninos, antes do momento previsto.

Ao propor sua teoria sobre o desaparecimento da infância, Postman (1999) nos encaminha a uma reflexão que se concluiria na extinção de tal etapa. No entanto, nos bastariam a quebra das zonas de segredo e o conseqüente acesso das crianças à informação, para a aceitação da morte da infância? À semelhança do que foi sugerido por Alcântara \& Campos (2006) observamos no presente diagnóstico social não um desaparecimento, mas um processo de reinvenção da infância, à medida que a identificamos como portadora de significações particulares às suas diversas novas formas de experimentar o mundo; e responder ao mesmo.

Podemos, no entanto, questionar que novas formas seriam estas das quais estamos falando; e que aspectos tornam este tempo da contemporaneidade único no que diz respeitos às relações estabelecidas entre as crianças e a mídia?

\subsection{Uma infância cheia de nouidades}

Segundo Steinberg \& Kincheloe (2001) vivenciamos a novidade de uma infância hiperealista, consumidora e socialmente ativa.

Hiperealista, pois seus integrantes estão inseridos em um contexto de vivência e familiarização com circunstâncias variadas através das quais recebem e experimentam uma 
gama de informações que extrapola a ordem do concreto, ou palpável, e se estende àquilo que toca o virtual ou é fruto de relações imaginárias. Estamos falando de uma geração que domina a tecnologia mesmo antes da alfabetização. Crianças e jovens que, quase, não têm tempo para interpretar o conteúdo daquilo que recebem (visto a rapidez e intensidade deste processo), e assim comprometem o exercício da criticidade. Além disso, há um cerceamento da criatividade das crianças, uma vez que vivem numa época onde os "brinquedos brincam sozinhos" (VENTURELLA, 2003, p.37) e não se faz necessário que elas inventem suas próprias regras e brincadeiras.

Dados de uma pesquisa realizada em 2003, pelo canal de tevê a cabo Cartoon Network, com 1.503 meninos e meninas, com idades de seis a onze anos, das classes socioeconômicas A, B e C, das cidades de São Paulo, Rio de Janeiro, Curitiba e Belo Horizonte constataram que $91 \%$ dos entrevistados recebem mesada; $81 \%$ passam mais de três horas diárias em frente à tevê; 36\% dizem que o programa preferido a se fazer com os pais é ir ao shopping; 54\% acessam a Internet freqüentemente; 58\% jogam videogame toda semana; $44 \%$ se preocupam com o peso e $36 \%$ escolhem o que vão comprar (VEIGA, 2003). Uma infância mais independente, ativa e, definitivamente, detentora da utilização de códigos específicos; no entanto, paradoxalmente, composta por indivíduos ainda em formação.

A criança e o adolescente atual estão em posição dúbia, pois ainda são vistos como necessitados de uma aprendizagem legitimada pela sociedade e, paralelamente, estão mais aptos que seus pais e professores para lidar com as novas tecnologias da vida cotidiana. (CAMPOS \& SOUZA, 2003, p.16).

Conforme citado anteriormente, a infância deste nosso tempo poderia ainda ser fortemente representada enquanto consumidora e socialmente ativa. McNeal (2000) é um dos autores que defendem a existência de uma atividade social exercida pelas crianças, à medida que se projetam e realizam enquanto consumidoras, neste mundo hiperealista. Segundo ele, as crianças representam três formas de mercado:

(1) um mercado primário de consumidores que gastam seu próprio dinheiro conforme seus desejos e necessidades; (2) um mercado de influência que orienta o gasto do dinheiro de seus pais em benefício próprio, e (3) um mercado de futuro de todos os bens e serviços que, se cultivados desde então, proporcionarão um fluxo constante de novos consumidores. (McNEAL, 2000, p.11). 
Além de terem participação real na decisão pelas compras da família; poderem fazer o que bem entendem com a mesada que ganham e corresponderem a futuros clientes, potencialmente, fiéis às marcas que por tantos anos consomem ou consumirão; a infância pode ser dita como socialmente ativa porque é estudada enquanto artefato social que vem sendo corporativamente trabalhado (STEINBERG \& KINCHELOE, 2001) para ser hedonista e destituído de inocência. Segundo estes autores, não é em vão que milhões de dólares são investidos, já há alguns anos, por grandes empresas de maneira a agregar às suas imagens aspectos como os de bondade, preocupação com o bem público e louvor a experiências rotineiras dos homens e mulheres ditos comuns; o que, na prática, não funcionaria da mesma forma. Kincheloe (2001) propõe, em outras palavras, que o mesmo McDonald's, que tanto preza pela instituição familiar em sua comunicação, não oferece espaço aos seus funcionários, mais comprometidos, para conviverem com as suas respectivas famílias. “... o declínio da vida familiar tradicional e a atmosfera de segurança para as crianças são uma casualidade do desenvolvimento das corporações". (GOLDMAN In: STEINBERG \& KINCHELOE, 2000, p. 30).

Ou seja, lidamos com um "consumo infantil projetado para jogar filhos contra pais e pais contra filhos numa batalha pela satisfação consumista" (STEINBERG \& KINCHELOE, 2000, p.30). A prática infantil deste câmbio multifacetado, nomeado consumo, se dá em um contexto onde a família e a escola não são mais as únicas fontes de informação e, consequentemente, uma fidelização que vai do berço ao túmulo (LINN, 2006) é instigada e facilitada pelas grandes corporações que sacrificam a lógica do indivíduo em função da lógica do sistema, visando, exclusivamente, o lucro que podem obter ante as tremendas oportunidades percebidas em anunciar para crianças.

\section{O meio Teleuisiuo}

Uma vez que a nossa discussão tem como temática central o instrumento da Classificação Indicativa que, por sua vez, se refere ao monitoramento de programações e produções audiovisuais, fica mais interessante a discussão quando se está a par da atuação e funcionamento dos meios que veiculam tais conteúdos. Um meio que bem figura a concepção de comunicação de massa e que, de acordo com a Pesquisa Nacional por Amostra de Domicílios (PNAD), do Instituto Brasileiro de Geografia e Estatística, está presente, com pelo menos um aparelho, em 91,4\% dos mais de 53 milhões de lares 
brasileiros, é a televisão. A ênfase do trabalho, discutida logo a seguir, repousará sobre alguns dos diversos modos de ocupação da tevê na sociedade contemporânea e seus respectivos efeitos para com os integrantes desta coletividade.

\section{Como "ele" funciona}

McLuhan apud Ferrés (1996) já falava acerca do fato de qualquer invenção técnica poder ser considerada uma espécie de extensão ou prolongamento de alguma faculdade humana. Ou seja, no caso do homem não poder se valer das mãos e braços para colher uma fruta em função da altura da árvore, por exemplo, poderia se utilizar de algum instrumento técnico para a efetuação da atividade de modo a conseguir coletar o fruto. Assim, numa próxima vez que o homem precisasse colher uma fruta, mais automaticamente, recorreria ao equipamento técnico, visto a facilidade de seu uso e garantia de satisfação. Ferrés (1996), no entanto, foi ainda além da concepção lógica que poderia ser aplicada à afirmativa do primeiro autor, propondo que "os meios não modificam somente uma faculdade" (p.15), mas todo o contexto físico e psíquico da pessoa, o seu entorno; alterando o modo como pensam, agem e percebem o mundo ao seu redor. Um automóvel, por exemplo, não seria uma simples extensão da função de transporte para o ser humano, mas conferiria, ao motorista, a possibilidade de se deslocar rapidamente, e assim se tornar mais impulsivo, impaciente, intolerante, etc. Isso só acontece quando os meios são assumidos pessoal e socialmente.

Assim também acontece com a tevê. Infindas são as possibilidades conferidas ao ser humano através deste meio, que extrapola o âmbito da comunicação, e é agente de modificação na relação que desenvolve com o ser humano, entre os seres humanos e ao redor dos mesmos, no contexto que os cerca. Segundo Ferrés (1998) o meio televisivo é detentor de um caráter mágico que faz parte de sua essência, não somente de seu conteúdo; e que fascinaria as pessoas, e conferiria àqueles que estão por trás das câmeras (os artistas) uma certa aura de infalibilidade.

Outro destaque se firma na possibilidade que a tevê tem de proporcionar a sensação de experimentação de novas coisas, lugares ou pessoas. Muito bem exemplificada pela fala de um dos participantes na atual propaganda institucional da emissora brasileira, Rede Globo de Comunicação - que diz algo semelhante a "se a gente não tem condições de viajar, vai pela televisão" - é a capacidade de mediação de experiências outras que o meio 
possui. Segundo Baudrillard (1991) não haveria diferença entre a imagem e a realidade, pois a era que experimentamos seria a do simulacro, na qual reprodução e originalidade se confundem. Ou seja, torna-se possível e, aparentemente, mais seguro assistir a um jogo de futebol dentro de casa, com direito a replay, e conforto, do que se dirigir a um estádio de futebol, por exemplo. Neste caso, tanto o telespectador quanto o torcedor, que marcou presença nas arquibancadas, sabem o resultado final da partida, são capazes de comentar os melhores e os piores lances, e ambos sentem-se, igualmente, participantes do espetáculo. Desta forma, os dois partilham as mesmas informações, só que mediadas de maneiras diferentes. No entanto,

Querer estar (...) em todos os lugares ao mesmo tempo significa não estar em lugar algum. Pretender ver tudo significa não ver nada. Querer saber de tudo leva a não saber nada. (FERRÉS, 1996, p.25).

Não se pode negar a sensação de empoderamento da situação que a mediação televisiva pode proporcionar, no entanto, remoto é o controle que se têm sobre um meio acerca do qual não se reflete ou levanta questionamentos.

De acordo com Ferrés (1996) estamos falando de um meio que gratifica o ser humano não só sensorialmente (em função dos estímulos visuais e sonoros que emite), mas também mentalmente (ao corresponder às expectativas míticas humanas, ou seja, a um mundo ideal que o homem precisa para complementar a realidade) e, ainda, psiquicamente (ao propiciar processos como os de projeção e identificação - descritos anteriormente - ao telespectador). O autor comenta, exatamente, sobre esta oferta ser, precisamente, daquilo que se quer e se deseja ver; o que resultaria numa estratégia comercialmente eficiente; e nutriria um ciclo onde o telespectador se alimenta, o tempo todo, de sua própria imagem.

\section{Alguns de seus efeitos}

Através do meio televisivo nos é permitido um re-conhecimento das coisas, ou seja, que as conheçamos novamente, por uma outra perspectiva; e nos é notória a penetração cultural que um meio de comunicação pode ter. Neste contexto é que a televisão surge como uma forma de socialização à medida em que se afirma enquanto veículo de promoção da informação, e esta última, por sua vez, se converte em forma de poder. Mas como assim?! Do que exatamente estamos falando? 
Em função do custo financeiro, relativamente baixo, necessário à obtenção de seu aparelho; e de uma existência que se dá através de uma linguagem facilmente compreendida que se vale de imagens para comunicar o que deseja, a televisão atinge um público extenso, sem restrições como as da alfabetização ou do recurso monetário. Uma informação pertinente a esta considerável aceitação que a televisão tem, junto à sociedade, reside na credibilidade que assume no repasse das informações. De acordo com a pesquisa Retratos da Fortaleza Jovem ${ }^{3}$ (realizada em 2007 pela prefeitura de Fortaleza-CE) dentre as atividades de Cultura e Lazer dos jovens entrevistados a TV se adequa como tal para 91,2\% deles (de segunda a sexta-feira) e para 89,8\% deles (nos finais de semana). E ainda para $64,1 \%$ destes jovens o telejornal se revela como única fonte de informação.

Um contexto onde a tevê é tida como fonte quase exclusiva de conhecimento da realidade (com o agravante deste ser um hábito já pertencente às camadas mais jovens da sociedade) nos desperta para noções como a de Controle Social, citada por Ferrés (1996). Segundo o autor, "a nossa imagem da realidade é basicamente aquela oferecida pela mídia e principalmente pela televisão" (p.59), forma pela qual se originaria a sua importância como meio de controle social. Ou seja, mantém-se uma ordem sob o trunfo da unidirecionalidade inerente ao meio e, converte-se, desta forma, informação em poder; enquanto se confere ao telespectador uma pseudo-sensação de liberdade. Falsa no sentido de que para que as pessoas sejam, verdadeiramente, livres não basta a ausência de coação física, mas torna-se imprescindível que saibam escolher e sejam internamente capazes de fazê-lo.

Assim sendo, por entender a mútua atividade da ação de educar é que pensamos que não devemos responsabilizar apenas a publicidade pela atmosfera de "má-educação" que paira sobre a sociedade; nem estender tal julgo exclusivamente sobre os meios de comunicação; nem tão pouco podemos nos eximir da responsabilidade de caminhar na direção oposta a tudo isto que constatamos ser o "porém" do nosso século. Dizemos

\footnotetext{
${ }^{3}$ Com o intuito de conhecer, identificar e mapear demandas e anseios das juventudes da cidade, e buscando oferecer mais um subsídio ao poder público e à sociedade civil na construção de políticas públicas voltadas para a mocidade, a Prefeitura Municipal de Fortaleza (Assessoria de Juventude do Gabinete da Prefeitura de Fortaleza) realizou a pesquisa Retratos da Fortaleza Jovem. A amostra compreende 1.734 sujeitos com idades de 15 a 29 anos (categoria, esta, subdividida em três faixas - 15 a 19 / 20 a 24 / 25 a 29) de 40 bairros da cidade. A aplicação do instrumento foi estruturada em 123 perguntas, referentes a entrevistas pessoais e domiciliares, com tempo médio de uma hora de aplicação; e margem de erro inferior a 5\% pontos percentuais, para mais ou para menos, para os resultados da amostra, com intervalo de confiança de $95 \%$. Acreditamos que os dados obtidos com esta pesquisa são relevantes ao nosso trabalho, por considerarmos estas informações como uma indicação do rumo que a juventude fortalezense está tomando, e o que isso revela enquanto futuro para as crianças que estão há poucos anos de se enquadrarem nesta realidade.
} 
"porém" (e não bem ou mal) por entendermos e considerarmos, desde este ponto da discussão, todo o paradoxo que circunda as relações tidas neste contexto da hiperealidade, da sociedade da informação e da familiarização dos pequenos com (e em) todos estes processos; e, portanto, atestarmos o tremendo potencial que a mídia tem para fazer a correnteza fluir para um lado, ou mesmo para o extremo oposto. Em um país, como o Brasil, onde $97 \%$ das famílias têm acesso cotidiano às transmissões das emissoras abertas ${ }^{4}$, a proposta de regulamentação das programações televisivas tem adentrado o cenário social como algo necessário à preservação de determinados valores, concretizado na proposta da Classificação Indicativa.

\section{Mas o que é Classificação Indicatiua, afinal?!}

O instrumento em questão se constitui enquanto política pública, cujo órgão responsável é o Ministério da Justiça - Departamento de Justiça, Classificação, Títulos e Qualificação; para o qual foi delegada a competência de:

III - instruir e analisar pedidos relacionados à classificação indicativa de diversões públicas, programas de rádio e televisão, filmes para cinema, vídeo e DVD, jogos eletrônicos, RPG (jogos de interpretação), videoclipes musicais, espetáculos cênicos e musicais;

IV - monitorar programas de televisão e recomendar as faixas etárias e os horários dos mesmos; (DECRETO N 4.720, DE 5 DE JUNHO DE 2003, ANEXO I, ARTIGO 12)

E, desta forma, fazer jus ao artigo 21 , XVI da $\mathrm{CF} / 88^{5}$, que dispõe o seguinte: "Compete à União: Exercer a classificação, para efeito indicativo, de diversões públicas e programas de rádio de televisão" (BRASIL, 2002).

A fundamentação da Classificação Indicativa está pautada sobre 5 (cinco) questões centrais, a saber:

1) a Classificação pode e deve ser compreendida como um instrumento de proteção e promoção dos direitos humanos, assim como uma ferramenta importante de diálogo com e de empoderamento da sociedade.

2) a criança e o adolescente, depositários de uma atenção absolutamente prioritária pelo Estado, pela sociedade e pela família, devem ser especialmente considerados neste processo.

\footnotetext{
4 Proporção extremamente semelhante ao conjunto de crianças matriculadas nas escolas de ensino fundamental. - Dados pertencentes à pesquisa recente da Unesco, veiculada na série Publicações da International Clearinghouse on Children, Youth and Media. (In_CANELA, 2006 p.53).

${ }^{5}$ Constituição Federal de 1988.
} 
3) a televisão, enquanto instituição emissora/produtora de conteúdos audiovisuais pode, e deve, ser democraticamente regulada pelos Estados nacionais.

4) a classificação Indicativa é um modelo de regulação específico que será tão, ou mais eficiente, quanto mais desenvolvidos forem os outros parâmetros do marco regulatório.

5) a classificação Indicativa não deve ser entendida como forma de censura ou como limitadora das visões mais avançadas acerca do conceito de liberdade de expressão. (CANELA, 2006 p.7).

Falar da Classificação Indicativa, proposta pelo Ministério da Justiça em parceria com outras organizações sociais, portanto, é falar de um serviço de análise de produções audiovisuais e de promoção e proteção dos direitos humanos, principalmente da criança e do adolescente, que já há quatro anos tem espaço no cenário nacional. De acordo com José Eduardo Romão, ${ }^{6}$ "em um país com a dimensão do nosso não se faz política sem meios de comunicação", o que enquadra a Classificação Indicativa na, delicada, categoria responsável pela promoção de um repensar dos interesses. Não estamos falando de censura, mas de um conjunto de procedimentos que registra uma decisão da sociedade (pois é apoiado e se reafirma nos movimentos sociais que lutam por uma mídia de qualidade para a infância e juventude brasileiras) e obriga o estado a reconhecer os direitos do povo. O começo de uma mobilização social que caminha rumo a uma democratização da comunicação e se choca com o interesse dos grandes grupos midiáticos/econômicos. Um meio para a finalidade de cuidar da juventude brasileira à qual se faz salutar o destaque do papel que os pais têm na assimilação de cada um dos processos, já descritos anteriormente. E é sobre a relevância da atuação social parental, para com a proposta da Classificação Indicativa, que deteremos a maior parte das observações da próxima etapa deste trabalho.

\section{Uma Parceria necessária}

Segundo Ferrés (1996), da mesma maneira que a alimentação dada às crianças tem uma enorme possibilidade de condicionar sua saúde e seus hábitos alimentares quando adultos, assim também se faz extremamente importante a postura que as famílias assumirão frente à televisão, uma vez que estão em jogo as marcas que para sempre

\footnotetext{
${ }^{6}$ José Eduardo Romão ex-diretor do Departamento de Justiça, Classificação, Títulos e Qualificação do Ministério da Justiça.
} 
acompanharão o tempo da primeira infância de futuros cidadãos. E mais que isso, marcas que poderão, também, interferir na atitude que terão frente à realidade.

O que fazer então? Levando em consideração a postura sensata do autor de que a telefobia $^{7}$, não leva a lugar algum e que, simultaneamente, não se pode adotar uma postura de pura ingenuidade para com o conteúdo e o meio televisivos; resta a tentativa de constante reflexão acerca não só do tempo de exposição das crianças a esta mídia, mas também do teor daquilo com o que terão contato; enquanto se possibilita uma formação adequada aos pais e/ou responsáveis destes pequeninos. Afinal, "a TV permite que a criança escolha o material de seus sonhos. Por outro lado, a criança precisa dos valores do espetáculo" (FERRÉS, 1996 p.102). E é neste cenário que a Classificação Indicativa surge como um instrumento de auxílio, às famílias, para a educação infanto-juvenil referente à mídia.

Buscando sondar como tem se dado este processo de assimilação da proposta da Classificação Indicativa, especificamente em Fortaleza-CE, é que adotamos uma metodologia de pesquisa que teve como objetivo principal "verificar qual a representação dos pais sobre a Classificação Indicativa e averiguar a existência de relevância deste instrumento para a família"8; e contou com métodos qualitativos e quantitativos de investigação; utilizando como critério a seleção de um público-alvo correspondente a pais e/ou responsáveis por crianças com faixa etária de 0 (zero) a 10 (dez) anos de idade, pertencentes às classes sócio-econômicas $\mathrm{C} 2, \mathrm{C} 1, \mathrm{~B} 2, \mathrm{~B} 1, \mathrm{~A} 2$ ou $\mathrm{A} 1$, residentes na cidade de Fortaleza-CE.

Com uma amostra de maioria feminina $(63,9 \%)$, pertencente ao intervalo de faixa etária que vai dos 26 aos 35 anos $(42,3 \%)$, com filhos que têm de 0 a 5 anos de idade (51,5\%), e que integra, em sua predominância, a classe socioeconômica A2 (36,8\%); a pesquisa (de caráter quantitativo) teve as perguntas elaboradas para o questionário cruzadas com tais dados demográficos resultando em uma série de informações das quais podemos destacar as seguintes:

\footnotetext{
7 Segundo Ferrés (1996), "deve-se evitar que os pais adotem atitudes apocalípticas diante da televisão, atitudes exageradas considerando-a causadora de todos os males". Afinal, "dificilmente as crianças entenderão que um meio que é para eles tão gratificante possa ser nocivo".

8 Tendo ainda como objetivos específicos:

- Constatar a existência (ou não) de diálogo, entre pais e filhos, sobre o conteúdo da programação televisiva assistida pelos mesmos;

- Investigar se, de fato, os pais estão cientes da existência do instrumento da Classificação Indicativa;

- Descobrir se estes pais consideram, no instrumento, relevância ao processo de educação de seus filhos.
} 
- Independentemente de sexo, faixa etária ou classe socioeconômica, os pais trabalham fora de casa. $\mathrm{O}$ fato de possuírem filhos menores de 5 anos de idade também não altera tal condição. $\mathrm{Na}$ amostra, $90 \%$ das pessoas com filhos de 0 a 5 anos revelaram trabalhar fora do ambiente residencial;

- $46,8 \%$ das mulheres entrevistadas passam até $8 \mathrm{hs}$ fora de casa, diariamente, enquanto $45,7 \%$ dos homens passam até $12 \mathrm{hs}$ fora de casa por dia;

- A Grande maioria dos entrevistados assiste televisão independentemente de faixa etária, sexo, ou classe socioeconômica;

- A metade dos entrevistados assiste TV todos os dias;

- Os filhos dos entrevistados têm contato com o meio televisivo. E a maioria deles conta com a presença da televisão em sua rotina, enfaticamente. $58 \%$ das crianças de 0 a 5 anos e $77,4 \%$ das crianças de 6 a 10 anos assistem TV todos os dias;

- $70 \%$ dos pais a partir de 46 anos têm algum tipo de regra para o consumo televisivo de seus filhos, enquanto entre os pais de 15 a 25 anos a porcentagem diminui para apenas $20 \%$;

- $20 \%$ dos pais de 15 a 20 anos acreditam que os filhos cumprem as regras estabelecidas, contra $60 \%$ dos pais com idade a partir de 46 anos. Dentre os citados a pesquisa registra, ainda, variação nas respostas dadas por homens e mulheres, onde, 53,2\% das mulheres acreditam na obediência dos filhos às regras de consumo televisivo pré-estabelecidas, e apenas $22,9 \%$ dos homens crêem desta mesma forma;

- $63,9 \%$ dos entrevistados disseram ter o hábito de conversar com seus filhos sobre àquilo que se assiste na TV;

- Aproximadamente metade das pessoas abordadas achou (mediante a descrição da proposta da Classificação Indicativa) que o instrumento seria útil e válido às suas realidades. Dentre esta porcentagem $62 \%$ têm filhos de 0 a 5 anos;

- A maioria dos entrevistados reconhece a simbologia da Classificação Indicativa embora a porcentagem de entrevistados da classe socioeconômica $\mathrm{C}$ que reconhece a simbologia seja menor (33\% da classe C contra 93,3\% da A1). O que pode indicar uma menor atenção e, conseqüente, reflexão sobre os detalhes inclusos/exibidos na programação ${ }^{9}$;

\footnotetext{
${ }^{9}$ Os resultados podem ainda ter sofrido algum tipo de oscilação pelo fato da maior parte da amostragem ser pertencente às classes socioeconômicas A e B.
} 
- A maioria das pessoas reconhece na simbologia a proposta da classificação Indicativa, apesar de não fazerem referência a esta nomenclatura, propriamente dita (90\% das pessoas acima de 46 anos reconhecem a simbologia como tal). As classes A e B identificam mais como Classificação Indicativa a simbologia,enquanto $66,7 \%$ da classe C sequer a reconhecem. A mesma dificuldade se apresenta para a etapa de reconhecimento ou familiarização com a nomenclatura;

- e 52,6\% dos entrevistados reconhecem a Classificação Indicativa como um recurso de auxílio à educação das crianças, no entanto, $15,5 \%$ dos entrevistados relacionaram a nomenclatura da Classificação Indicativa à censura.

A pesquisa de cunho qualitativo, por sua vez, confirmou a maioria das informações acima citadas e nos permitiu considerar ainda outras questões. Um aspecto interessante, até então, não hipotetizado por nós, foi uma concepção da Classificação Indicativa enquanto repasse de responsabilidade sobre o conteúdo midiático consumido pelas crianças. A afirmativa dos pais, que integraram o grupo de discussão, apontava que a emissora de televisão estaria se eximindo da responsabilidade sobre o conteúdo midiático, delegando-a aos pais e familiares. O que revela, por parte deles, uma falta de perspectiva para $\mathrm{o}$ potencial de parceria que deve existir entre a família, a sociedade e as instituições de ensino (escola, mídia, etc.). Afinal, apesar de à mídia realmente caber uma preocupação com a responsabilidade social, não podemos ignorar o fato de que as empresas concessionárias são, na maioria das vezes, enormes corporações que visam o lucro; e que os pais e responsáveis são, sim, os maiores interessados no bem-estar de seus filhos ${ }^{10}$.

Para nossa surpresa, ainda uma outra informação veio à tona. $\mathrm{O}$ percentual de entrevistados que classificou o instrumento enquanto censura não foi alto (apenas 15,5\%, conforme citado anteriormente). No entanto, diferentes são as concepções que as pessoas podem assumir sobre censura, ora vinculando-a ao tolhimento da liberdade de expressão, ora, simplesmente, fazendo menção a uma nomenclatura habitualmente utilizada; o que também representou uma dificuldade para a compreensão dos dados coletados na etapa

\footnotetext{
${ }^{10}$ É relevante a observação que diz respeito à relação de cada um dos participantes com o lado profissional da comunicação. De acordo com as fichas de recrutamento, todos os membros integrantes da pesquisa qualitativa têm um parente ou amigo próximo que trabalha com comunicação (publicidade, jornalismo, etc.), veículo de mídia (revista, televisão, etc.) ou mesmo é um profissional de alguma destas áreas. Havendo, ainda, um dos integrantes, também, relacionado com o próprio Ministério da Justiça. A discussão, no entanto, não revelou aspectos significativos indicadores da existência desta relação, aproximando-se o discurso dos participantes daquilo que fora anteriormente sugerido como hipótese, em inferências às prováveis respostas de senso comum.
} 
quantitativa, pois a amplitude do questionário não comportava tal especificidade; mas pôde ser um pouco mais observado ${ }^{11}$ e esclarecido na discussão feita em grupo. Quando ainda há registros de menção à censura, todo cuidado se faz necessário afim de que se preserve o caráter de livre expressão atrelado à proposta da Classificação Indicativa.

\section{Considerações Finais}

Ao constatarmos estar experimentando uma sociedade neoliberal, em que os meios de comunicação provam, todos os dias, seu alcance e a eficiência com que comunicam suas mensagens, pode ser dita enquanto urgente a necessidade do desenvolvimento de iniciativas que atuem na defesa e promoção dos direitos humanos; e contribuam para uma re-educação social.

A Classificação Indicativa, proposta pelo Ministério da Justiça em parceria com organizações civis, é apenas uma delas. Uma iniciativa que ainda têm um longo caminho de aperfeiçoamento pela frente. Que, conforme averiguamos, existe para determinadas famílias e crianças ${ }^{12}$. E que poderia considerar se valer de métodos de comunicação eficientes à extensão de sua proposta, desvinculando-a da concepção de censura, e relacionando o seu potencial de intervenção social a uma parceria estabelecida com os pais.

Os pais. Agentes fundamentais da promoção da noção de cidadania às crianças e adolescentes; responsáveis por inculcar os valores que, por muitos anos, senão para sempre, acompanharão esta minoria. A sensação é a de que uma enorme carga repousa sobre estes educadores e, de fato, assim o é. Afinal, desde quando se é inerente a arte do saber educar?! E quem na realidade o faz com maestria? Indispensáveis às propostas de utilização da ferramenta da Classificação Indicativa, os pais precisam sentir-se amparados pelo Estado e pela Mídia. Desafio gigantesco a uma sociedade individualista que preza pelo benefício de grandes corporações.

O compromisso com a transformação do mundo precisa ser incorporado à essência de seus cidadãos e, mais que isso, estar entranhado às suas ideologias. Na luta pela defesa e promoção dos direitos das crianças e dos adolescentes todas as iniciativas são válidas.

\footnotetext{
${ }^{11}$ Fez-se interessante perceber que até o momento, propositalmente deixado para o final da discussão, em que a mediadora levantou questionamentos acerca da relação existente entre a Classificação Indicativa e a censura, ninguém havia se referido ao instrumento enquanto tal, uma vez sequer. Após a primeira menção ao termo, os participantes passaram a inserir em seu discurso a palavra "censura".

${ }^{12}$ Não havendo cerceamento da categoria que utilizaria o instrumento apenas por segmentações referentes a sexo, faixa etária, nem tão pouco, classe socioeconômica.
} 
Umas com menos, outras com mais visibilidade; sendo todas importantes à construção de uma história de cuidados e investimentos para com os pequenos brasileirinhos. Esperamos ter conseguido adubar, um pouquinho mais, essa plantação que, se bem cuidada, promete uma colheita e tanto para esta e outras estações.

\section{Referências Bibliográficas}

ALCÂNTARA, Alessandra; CAMPOS, Marília. Agora eu era o Rei: a reinvenção da Infância. In: SAMPAIO, Inês; CAVALCANTE, Andréa; ALCÂNTARA, Alessandra (orgs.). Mídia de Chocolate, estudos sobre a relação infância, adolescência $e$ comunicação. Rio de Janeiro: E-papers, 2006.

BAUDRILLARD, J. Simulacros e simulação. Lisboa: Relógio d’Água, 1991.

CAMPOS, Cristiana Caldas G. de; SOUZA, Solange Jobim e. Mídia, cultura do consumo e constituição da subjetividade na infância. Psicologia, ciência e profissão. $\mathrm{N}^{\mathrm{o}}$ 1, V. 23, p. 12-21, 2003.

CANELA, Guilherme (org.) Classificação Indicativa: Construindo a Cidadania na tela da Tevê. Brasília: ANDI; Secretaria Nacional da Justiça, 2006.

FERRÉS, Joan. Televisão e Educação. Porto Alegre: Artes Médicas, 1996.

Televisão Subliminar. Socializando através de comunicações despercebidas. Porto Alegre: Artmed, 1998.

FNDC - Fórum Nacional pela Democratização da Comunicação. País anseia por amplo debate sobre as Comunicações. MídiaComDemocracia. n.7, ano, p.9-12, Fev. 2008.

LINN, Susan. Crianças do consumo: a infância roubada. São Paulo: Instituto Alana, 2006.

McNEAL, J. U. Children as consumers of comercial and social products. Washington: Pan American Health Organization, 2000.

POSTMAN, Neil. O desaparecimento da infância. Rio de Janeiro: Graphia, 1999.

STEIBERG, Shirley R.; KINCHELOE, Joe L. Cultura infantil, a construção corporativa da infância. Rio de Janeiro: Civilização Brasileira, 2001.

VENTURELLA, Valéria. A influência da mídia na formação da criança hoje. Hífen. n.51, V. 27, p. 37-44, 2003.

\section{Legislação}


BRASIL. Constituição Federal de 1988. 19ª ed. Brasília-DF: Câmara dos Deputados, 2002. 